\title{
A NATUREZA JURÍDICA DO ACESSO À INTERNET PARA O DIREITO
}

\author{
Sérgio Rosa BANDEIRA ${ }^{1}$ \\ Wagner Saraiva Ferreira Lemgruber BOECHAT ${ }^{2}$ \\ Mariane Silva PARÓDIA ${ }^{3}$ \\ Malu Maria de Lourdes Mendes PEREIRA ${ }^{4}$
}

Recebido em: 05/10/2015 - Aprovado em: 02/12/2015 - Disponibilizado em: 18/01//2016

\begin{abstract}
Resumo: O presente artigo tem como objetivo trazer à luz o que é o acesso à Internet para a ciência jurídica, para que assim, após o devido enquadramento em um instituto jurídico, seja possível o correto tratamento do mesmo no âmbito do Direito. Para tanto, foi necessária uma pesquisa bibliográfica e entender como encaixar um recurso tecnológico dentro da seara do Direito. Assim, as referências não estão apenas resumidas ao mundo da ciência jurídica, houve a necessidade de buscar outras fontes como sites com dados estatísticos e adentrar na área da Tecnologia da Informação. Adotou-se o método hipotético dedutivo. O trabalho se mostrou relevante e urgente devido à incerteza do tratamento do tema, uma vez que a Ciência Jurídica tem se atido somente à presença dos direitos na Rede, mas não à própria natureza da Internet. Concluiu-se que o acesso à Internet é direito sui generis, pois é infraconstitucional mas goza de prerrogativas de direito fundamental.Trata-se de artigo elaborado pelo Grupo de Estudos de Facetas dos Direitos Difusos e Coletivos.
\end{abstract}

Palavras-chave: Internet, direitos, Marco Civil.

\footnotetext{
${ }^{1}$ Advogado, Bacharel em Direito pela Universidade Vale do Rio Verde. E-mail: estudosdedireitoaplicado@gmail.com

${ }^{2}$ Advogado, consultor ambiental, professor de Direito na Universidade Vale do Rio Verde e Faculdade de São Lourenço. Graduado em Direito pela Faculdade de São Lourenço, pós-graduado em Direito Público pela Faculdade de São Lourenço, em Direito Tributário pela Fundação Getúlio Vargas, Direito Ambiental e Urbanístico pelo Centro Anhanguera de Promoção e Educação Social e mestre em Direito linha Constitucionalismo e Democracia - pela Faculdade de Direito do Sul de Minas Gerais. E-mail: estudosdedireitoaplicado@gmail.com

${ }^{3}$ Advogada, professora universitária e especialista em Direito Civil pela Universidade Anhanguera. Email: estudosdedireitoaplicado@gmail.com

${ }^{4}$ Auditora Fiscal da Receita Estadual (MG) e professora de Direito Administrativo e Direito Civil na Faculdade de Direito de São Lourenço/MG (UNISEPE). Graduada Direito e em Comunicação Social, pós-graduada e Mestre em Direito Constitucional pela Faculdade de Direito do Sul de Minas (FDSM). Também possui especializações em Direito Tributário, Direito do Estado, Direito Civil e Direito Notarial e Registral. É frequentadora dos cursos intensivos válidos para o doutorado em Direito Constitucional da Universidad de Buenos Aires, já tendo concluído os créditos. E-mail: estudosdedireitoaplicado@gmail.com
} 


\section{Introdução}

$\mathrm{O}$ presente artigo tem como objetivo discutir e estabelecer a natureza jurídica do acesso à internet no Brasil.

Para tanto, explorar-se-á alguns institutos jurídicos para saber qual melhor se adequa a natureza do acesso àRede Mundial de Computador.

Tal tarefa, a princípio, se torna dificultosa, principalmente por se tratar de tema recente ainda inexplorado pela doutrina, porém uma resposta apresenta-se possível por meio de uma busca entre os ramos da ciência jurídica.

Assim adotar-se-á o método de pesquisa bibliográfico e hipotético dedutivo.

Importante ressaltar que sem a devida compreensão do que é a Internet para o Direito, todos os direitos que dependem do mundo digital se quedam à mercê de entendimentos arbitrários e a própria sociedade atual resta prejudicada e sem segurança jurídica.

Portanto o problema aqui proposto de qual é a natureza jurídica do acesso à Internet cobre lacunas legislativas e se apresenta para a sociedade como ponto essencial a sua continuidade.

Este artigo foi elaborado por estudantes e pesquisadores do Grupo de Estudos Facetas dos Direitos Difusos E Coletivos, que visa congregar preferencialmente pesquisas de cunho teórico, bibliográfico e com o método hipotético dedutivo que se dirijam aos ramos dos Direitos coletivos e difusos; bem como estudar as interações jurídicas formadas a partir de diplomas jurídicos que estatuem direitos a princípio individuais, mas que, devido às interações do sistema jurídico ou da sociedade, apresentam reflexos difusos ou coletivos.

\section{A Internet e a Sociedade Atual}

Se hoje um livro de história contemporânea fosse aberto, quer para um estudo profundo ou para uma simples consulta, dificilmente não seria feita uma referência sobre a Internet. Não é exagero afirmar que a rede mundial de computadores seja a tecnologia mais importante e influente da atual sociedade, pois ela moldou o mundo, facilitando o processo de globalização e se estendendo muito além do domínio acadêmico e econômico.

Com a expansão da estrutura da Rede e o consequente aumento de sua velocidade, surgiram novas funcionalidades e serviços, o que permitiu um maior alcance e sua respectiva popularização.

Tal fato é axiomático, porém um sistema tão versátil e com funções ainda não totalmente exploradas logo seria de interesse de outros ramos, incluindo o Direito.

Hoje muito é falado sobre a liberdade de expressão na Rede e o quanto o exercício da mesma é possível de forma plena dentro do 
ambiente virtual. Impossível não falar também da facilitação do acesso à educação, à informação, além dediversos serviços essenciais.

Assim, é preciso definir o que é o acesso à Internet para o Direito para que seja possível dar o devido tratamento a mesma no plano jurídico.

\section{O que é a Internet e qual a sua importância}

$\mathrm{O}$ mundo inteiro utiliza a Internet, porém são poucos os que poderão dar uma definição completa da mesma. Não há nada de estranho nisso, uma vez que, em regra, os maiores interessados no acesso à Rede são os usuários finais.

No presente artigo a definição torna-se importante para que seja dado o correto tratamento a Internet na Ciência do Direito.

A Internet pode ser definida como "uma teia de âmbito mundial formada por redes universitárias, comerciais, militares $e$ cientificas interconectadas". (LAQUEY; RYER, 1994, p.28). Esta definição coaduna com os dizeres do Marco Civil da Internet (Lei 12.965/2014), vigente no ordenamento jurídico brasileiro:

Art. $5^{\circ}$ Para efeitos desta Lei, considera-se:

I - Internet: o sistema constituído do conjunto de protocolos lógicos, estruturado em escala mundial para uso público e irrestrito, com a finalidade de possibilitar a comunicação de dados entre terminais por meio de diferentes redes; (Brasil, 2014)

Se a Internet é uma 'teia', então como é o seu 'desenho'?

Segundo Laquey e Ryer (1994), a complexidade da sociedade é tamanha que a tarefa de desenhar essa teia com todas as suas ligações é hercúlea, e, sendo assim, a Rede é mais retratada sob a forma de uma nuvem.

Apesar de toda esta descentralização, isto não quer dizer que a Internet não seja organizada ou não tenha órgãos que desempenhem papéis importantes para a manutenção de sua estrutura. Um desses órgãos é o Internet Corporation for AssignedNameandNumbers ${ }^{5}$ (ICANN), corpora ção internacional sem fins lucrativos, responsável pela alocação do espaço de endereços de Protocolos da Internet (IP), pela atribuição de identificadores de protocolos, pela administração do sistema de domínios e também pelas funções de gerenciamento do sistema de servidores-raiz. Sem a existência desse órgão ou de algum semelhante a esse, não seria possível fazer $\mathrm{o}$ acesso a sites através de endereços nominais, e sim numéricos (Ex.: Ao invés de acessar o site do Planalto digitando $w w w . p l a n a l t o . g o v . b r$ seria necessário digitar um número como 127.123.123.123)(ICANN Meeting São Paulo, 2015). Assim, a existência do ICANN, na verdade facilita o acesso dos usuários por meio de um manuseio mais simples.

${ }^{5}$ Corporação para Atribuição de Nomes e Números na Internet 
Toda esta estrutura interligada mundialmente provocou profundas transformações na sociedade. Não é exagero dizer que a Internet foi a mola mestra para a 'revolução digital'. Praticamente todas as atividades humanas foram de alguma forma afetadas com a expansão da Rede. Hoje estão à disposição digitalmente uma infinidade de serviços que antes exigiam uma enorme demanda de material outrâmite burocrático moroso.

Socialmente e economicamente é inegável a importância da Internet. O aumento constante da velocidade de acesso à rede é proporcional à expansão do número de usuários. A título de comparação: no ano de 2000 existiam, no mundo, cerca de 360 milhões de usuários conectados e em 2014 este número saltou para um pouco mais de 03 bilhões de usuários, um crescimento de $741 \%$ no período (Internet World Stats, 2014). Hoje as empresas se relacionam de forma instantânea fazendo milionários negócios online. Governos abriram canais de acesso que além de facilitar a vida do cidadão, também criaram formas de controle mais rígidos, impactando profundamente o campo tributário (Brasil, 2015).

Com o tempo, a Internet deixou de ser apenas um meio de comunicação com objetivos econômicos ou acadêmicos, tornouse uma nova forma de se expressar, de se ter voz. Basta uma rápida pesquisa na Rede para que seja possível encontrar desde opiniões relevantes sobre diversos assuntos até ativismo político. Indo mais além, a rede mundial começou a oferecer serviços estatais de grande importância para o exercício da cidadania.

Diante de tal quadro o Direito não poderia se manter inerte. Quanto aos abusos e crimes cometidos pela Rede já existe uma boa base de estudos e ferramentas jurídicas tratando deste tema, entretanto a classificação do acesso à Internet em si, no Direito, ainda é obscura.

\section{A Internet versus acesso à Internetno mundo jurídico}

Para queo acesso à Internet seja tratado de forma correta dentro do Direito é necessário primeiro definir o que é Internet para ciência jurídica.

Sendo assim, é importante a análise sobre o que é a Rede dentro de alguns institutos jurídicos e ainda salientar o que importa para a ciência jurídica: a Internet enquanto sistema ou o acesso a ela.

No Direito Civil, pode-se questionar se a Internet é um bem.

Bens são definidos como

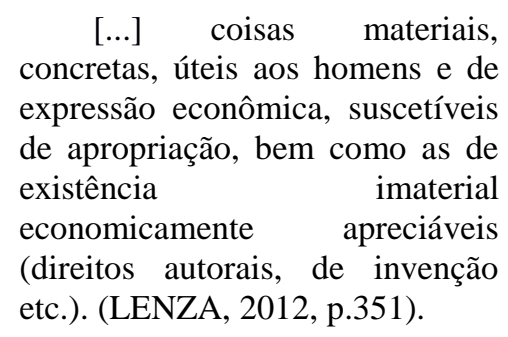

Conforme exposto, é inegável a 
expressão econômica da Internet e sua utilidade, porém a mesma é impossível de apropriação por se tratar de uma rede interligada mundialmente sem centralização.

Vale dizer entretanto que o domínio nome que serve para localizar e identificar conjuntos de computadores na Internet - é considerado um bem, uma vez que os requisitos para que assim o caracterize estão presentes (The Next Web, 2013).

Quanto ao acesso à Internet, a sua disponibilidade é enquadrada como serviço, devidamente tratado no ordenamento jurídico pelo Código de Defesa do Consumidor e o Código Civil, além de regulamentos da Agência Nacional de Telecomunicações (ANATEL).

Em resumo, a Internet não é um bem, o que não quer dizer que alguns de seus 'componentes', não possam ser classificados como tal. O que se pode ter universalmente é o acesso à rede mundial como serviço, que pode abarcar tanto a esfera consumerista quanto civilista. E é o acesso à rede mundial de computadores que interessa ao presente artigo.

Em que pese à classificação do acesso à Internet como serviço, isto não quer dizer que $\mathrm{o}$ assunto se esgota. $\mathrm{O}$ legislador brasileiro inovou recentemente com o Marco Civil da Internet, dando novo tratamento ao assunto e indo muito além do aspecto econômico.

\section{O acesso à Internet como direito no Marco Civil da Internet}

O Marco Civil da Internet expandiu o entendimento sobre o que é o acesso à Internet, saindo da seara econômica, dando novas interpretações além da já explanada classificação do acesso como um serviço.

Entre os diversos princípios que disciplinam o uso da Internet no Brasil, o Marco Civil elenca o objetivo da promoção do acesso à Rede como um direito a todos:

Art. $4^{\circ}$ A disciplina do uso da internet no Brasil tem por objetivo a promoção:

I - do direito de acesso à internet a todos; (BRASIL, 2014).

Em que pese o tratamento como direito ordinário, se faz necessário salientar a importância deste tipo de direito quando tratado em legislação infraconstitucional:

\footnotetext{
Sem a legislação ordinária, a Constituição - e todos os valores que encerra - não pode converterse em Direito no dia-a-dia das pessoas, dada a abstração dos seus conteúdos. $\mathrm{O}$ que se percebe com essa abordagem é que para se garantir o pluralismo, a Constituição deve conter normas abertas, cuja concreção corresponde mais ao legislador, do que ao juiz, o que justifica a existência de um grande número de normas constitucionais estatuídas na forma de princípios ou de valores (DUQUE, 2005, p. 19).
}

Neste contexto, avançando sobre o assunto, é preciso correlacioná-lo com os direitos humanos e direitos fundamentais, pois, apesar do acesso à Internet ser tratada no ordenamento brasileiro como um direito 
ordinário, previsto em lei infraconstitucional, impossível não haver influência nos direitos 'hierarquicamente superiores'.

\section{O acesso à Internet e os direitos humanos}

A primeira análise possível é se há possibilidade de qualificar o acesso à Internet como um direito humano, iniciando pela definição deste tipo de direito.

Para Bobbio (1992, apud PIOVESAN, 2012):

os direitos humanos nascem como direitos naturais universais, desenvolvem-se como direitos positivos particulares (quando cada Constituição incorpora Declaração de Direitos) para finalmente encontrar a plena realização como direitos positivos universais.

Conforme exposto, não há como enquadrar um sistema eletrônico como um direito natural e universal, o que não quer dizer que através do acesso ao mesmo não seja possível o exercício dos direitos humanos.

Um direito humano que pode ser exercido na Internet, como exemplo, é o direito à liberdade de opinião e de expressão, encontrado na Declaração Universal dos Direitos Humanos:

Artigo XIX: Todo o indivíduo tem direito à liberdade de opinião e de expressão, o que implica o direito de não ser inquietado pelas suas opiniões e o de procurar, receber e difundir, sem consideração de fronteiras, informações e ideias por qualquer meio de expressão (ONU, 1948).

A facilidade que a Internet trouxe para o exercício deste direito é um fato axiomático, basta um rápido acesso para que diversas formas de expressão e opinião estejam à disposição. Vale dizer que, ao aprofundar no assunto, é fácil identificar outros direitos humanos que podem ser exercidos através da rede mundial.

O Marco Civil da Internet também disciplina o uso da Internet no Brasil com fundamento nos direitos humanos:

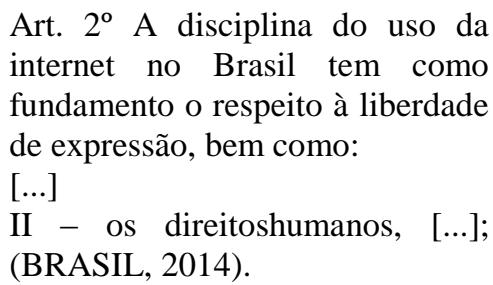
internet no Brasil tem como fundamento o respeito à liberdade de expressão, bem como:

[...]

II - os direitoshumanos, [...]; (BRASIL, 2014).

A ONU se pronunciou quanto à importância da Internet para o exercício dos direitos humanos:

Given that the Internet has become an indispensabletool for realizing a range of human rights, combating inequality, and accelerating development and human progress, ensuring universal access to the Internet should be a priority for all States. Each State should thus develop a concrete and effective policy, in consultation with individuals from all sections of society, including the private sector and relevant Government ministries, to make the Internet widely available, accessible and affordable to all segments of population (ONU, 2011, p.22).

Portanto o acesso à Internet aparece atualmente como indiscutível meio de efetivação dos direitos humanos, gozando 
reflexivamente de algumas das suas prerrogativas.

\section{O acesso à Internet e os direitos} fundamentais

Os direitos fundamentais, desenvolvidos principalmente com $\mathrm{O}$ surgimento das constituições modernas, "são uma aquisição evolutiva tipicamente moderna e pretenderam responder a uma nova necessidade de uma sociedade que se afirmava diferente das anteriores e, portanto, moderna." (OMMATI, 2014, P.38). Ainda pode-se entender, conforme Ommati (2014), que os direitos fundamentais são mecanismos indispensáveis para que os direitos humanos sejam tratados de forma a atender o anseio social em cada ordenamento jurídico.

Em que pese a importância do acesso à Internet e sua influência na sociedade, o legislador pátrio preferiu tratar o assunto em lei infraconstitucional e não na Constituição, o que não quer dizer que não haja reflexos nas previsões legais contidas na Carta.

Nesse sentido,o Marco Civil se relaciona com os direitos fundamentais elencados no art. $5^{\circ}$ da $\mathrm{CF} / 88$ :

Art. $5^{\circ}[\ldots]$

IV - é livre a manifestação do pensamento, sendo vedado $\mathrm{o}$ anonimato;

[...];

IX - é livre a expressão da atividade intelectual, artística, científica e de comunicação, independentemente de censura ou licença;

$[\ldots]$
XIV - é assegurado a todos o acesso à informação e resguardado o sigilo da fonte, quando necessário ao exercício profissional; (BRASIL, 1988).

Quanto ao direito à comunicação, a Constituição da República de 1988 a prevê não só no inciso IX do art. $5^{\circ}$, como também o exercício da mesma no caput do art. 220, que diz que "nenhuma manifestação do pensamento, a criação, a expressão $e$ a informação, sob qualquer forma, processo ou veículo não sofrerão qualquer restrição, observado o disposto na Constituição" (BRASIL, 1988).

Quando analisados os dispositivos legais, não é exagero a conclusão de que somente a Internet livre e independente conseguiu garantir o exercício pleno do direito à comunicação, com um mínimo de custo, pois basta que o indivíduo, a princípio, tenha apenas um ponto de acesso disponível.

$\mathrm{O}$ art. $7^{\circ}$ do Marco Civil também prevê o acesso à Internet como essencial ao exercício da cidadania - um dos fundamentos do Estado Brasileiro, conforme o art. $1^{\circ}$, II, $\mathrm{CF} / 88$. Coaduna com isso o fato de que, diante da diversidade de serviços estatais oferecidos online atualmente, a previsão legal, destacando a essencialidade do acesso ao exercício da cidadania, torna-se importante.

Nesse sentido, o relatório da ONU, já citado nesse artigo, é bem claro quanto a importância sobre um desenvolvimento de uma política sobre o assunto, com a participação de toda a sociedade, inclusive, o 
setor privado.

Portanto o acesso à Internet, tampouco

pode ser classificado como direito

fundamental, mas tem a cada dia se fundido

mais com esses, de modo que paulatinamente

vem se tornando indivisível dos mesmos a

medida que é meio de seu exercício.

\section{Restrição ao acesso à Internet}

\section{Enquanto instrumento para o exercício}

dos direitos humanos e fundamentais, a

Internet deve ser protegida de ações que cerceiem o fluxo de dados; como ocorre em alguns Estados que utilizam meios autoritários para bloquear o acesso à Rede.

A China é um grande exemplo de bloqueio de conteúdo online. O relatório da ONU cita-a:

Blocking refers to measures taken to prevent certain content from reaching an enduser. This includes preventing users from accessing specific websites, Internet Protocol (IP) addresses, domain name extensions, the taking down of websites from the web server where they are hosted, or using filtering technologies to exclude pages containing keywords or other specific content from appearing. For example, several countries continue to block access to YouTube, a video-sharing website on which users can upload, share and view videos. China, which has in place one of the most sophisticated and extensive systems for controlling information on the Internet, has adopted extensive filtering systems that block access to websites containing key terms such as "democracy" and "human rights". The Special Rapporteur is deeply concerned that mechanisms used to regulate and censor information on the Internet are increasingly sophisticated, with multi-layered controls that are often hidden from the public (ONU, 2011, p.9).

Por outro lado, vale salientar que o acesso à Rede Mundial de Computadores não é um direito absoluto, podendo ser mitigado em casos bem específicos, porém nunca para cercear a liberdade de opinião:

Imprisoning individuals for seeking, receiving and imparting information and ideas can rarely be justified as a proportionate measure to achieve one of the legitimate aims under article 19, paragraph 3 , of the International Covenant on Civil and Political Rights. The Special Rapporteur would like to reiterate that defamation should be decriminalized, and that protection of national security or countering terrorism cannot be used to justify restricting the right to expression unless the Government can demonstrate that: (a) the expression is intended to incite imminent violence; (b) it is likely to incite such violence; and (c) there is a direct and immediate connection between the expression and the likelihood or occurrence of such violence.

Additionally, the Special Rapporteur reiterates that the right to freedom of expression includes expression of views and opinions that offend, shock or disturb. Moreover, as the Human Rights Council has also stated in its resolution 12/16, restrictions should never be applied, inter alia, to discussion of Government policies and political debate; reporting on human rights, Government activities and corruption in Government; engaging in election campaigns, peaceful demonstrations or political activities, including for peace or democracy; and 
expression of opinion and dissent, religion or belief, including by persons belonging to minorities or vulnerable groups (ONU, 2011, p.11).

Portanto, o acesso à Internet ao se tornar direito ordinário e garantidor de direitos fundamentais e humanos, dos quais guarda cada vez mais intimidade e indivisibilidade, não pode ser cerceada sem a devida justificativa através do devido processo legal.

\section{Conclusão}

A Internet faz parte da vida cotidiana de todos e as mudanças trazidas por ela são inegáveis. A Rede, enquanto sistema, cresce cada vez mais, com contornos que podem levar a sua onipresença na sociedade. Assim o Direito deve se adequar a essa realidade, pois as relações humanas estão agora acontecendo no mundo virtual.

Por isto, a ciência jurídica deve tratar adequadamente o acesso à Internet.

Importante ressaltar, em que pese a possibilidade de analisar o acesso à Internet enquanto serviço, a sociedade, pelo seu próprio uso que faz deste meio de comunicação, dá uma importância muito maior, podendo facilmente ser enxergada de forma diferente, como uma extensão das relações sociais.

Assim, após a exposição de alguns institutos jurídicos e as devidas explanações sobre eles, conclui-se que, apesar de a Internet não poder ser considerada um bem ou um direito em si, o acesso a ela é considerado um serviço na esfera consumerista.

Porém deve-se entender que o enquadramento como serviço não reflete a envergadura concedida pelo Marco Civil da Internet, pois segundo tal diploma, o acesso à Rede é um direito per si, o que o diferencia de outros serviços. Assim se pode afirmar que o acesso é um direito que se traduz em um serviço.

Ocorre que mesmo essa dimensão não é capaz de abarcar a natureza jurídica, já que, devido à potencialidade dos usos e possibilidades da Internet, o enquadramento infraconstitucional é insuficiente para comportar a envergadura de tal direito.

O acesso à Internet não somente é direito, mas também é instrumento fundamental de efetivação de outros tantos direitos, os quais se originam de instâncias muito mais superiores por se enquadrarem no campo fundamental e de direitos humanos.

Assim o acesso é um direito sui generis, cujo caráter garante a efetivação dos direitos humanos, dos direitos fundamentais e do exercício da cidadania, adquirindo reflexivamente algumas de suas garantias e, portanto,somente podendo ser restringido em casos especialíssimos e guardado o devido processo legal para isso.

Vale finalmente dizer que quanto mais consolidada a rede mundial de computadores, maior será a sua importância para a ciência jurídica, em um contínuo processo de 
sedimentação de direitos que dependerão progressivamente do acesso à Internet.

\section{REFERÊNCIAS}

BRASIL. Código Civil (Lei 10.406/2002).

Disponível em:

<http://www.planalto.gov.br/ccivil_03/leis/20 02/L10406compilada.htm>. Acesso em: 07/06/2015.

BRASIL. Código de Defesa do Consumidor (Lei 8.078/90). Disponível em: < http://w ww.planalto.gov.br/ccivil_03/leis/L8078comp ilado.htm>. Acesso em: 07/06/2015.

\section{BRASIL. Constituição da República} Federativa do Brasil de 1988. Disponível em: <

http://www.planalto.gov.br/ccivil_03/constitui cao/constituicaocompilado.htm>. Acesso em: 06/06/2015.

\section{BRASIL. Marco Civil da Internet (Lei}

\subsection{5/2014). Disponível em:}

<http://www.planalto.gov.br/ccivil_03/_ato20 11-2014/2014/lei/112965.htm>. Acesso em: $31 / 05 / 2015$.

BRASIL. No ano de 2015 a Receita Federal do Brasil recebeu 27.895.994 declarações de imposto de renda. Disponível em: $<\mathrm{http}$ ///idg.receita.fazenda.gov.br/noticias/asc om/2015/maio/balanco-final-do-irpf-2015receita-recebeu-27-895-994-declaracoes $>$. Acesso em: 31/05/2015.

\section{DUQUE, Marcelo Schenk. A Importância} do direito ordinário frente à supremacia da Constituição. 38f. Artigo (Doutorado em Direito do Estado) - Universidade Federal do Rio Grande do Sul, Porto Alegre, 2005.

Disponível em:

<seer.ufrgs.br/index.php/ppgdir/article/downl oad/43496/27374> . Acesso em: 20/06/2015.

ICANN Meeting São Paulo. Sobre o ICANN. Disponível em:
$<$ http://www.icannsaopaulo.br/port/sobreicann.htm>. Acessoem: 31/05/2015.

INTERNET WORLD STATS.Internet Usage Statistics - The Internet Big Picture - World Internet User and 2014 Population Stats.Disponível em: < http://www.internetworldstats.com/stats.htm> . Acesso em: 31/05/2015.

LAQUEY, Tracy; RYER, Jeanne C. O Manual da Internet: Um Guia Introdutório para Acesso as Redes. São Paulo: Campus, 1994. 270p.

LOPES, José Reinaldo de Lima. Direitos sociais: teoria e prática. São Paulo: Método, 2006. 303p.

ONU - OFFICE OF THE HIGH COMISSIONER FOR HUMAN RIGHTS. Universal Declartion of Human Rights. 1948. Disponível em: <http://www.ohchr.org/EN/UDHR/Pages/Lan guage.aspx?LangI]D=por $>$. Acesso em: 06/06/2015.

ONU - OFFICE OF THE HIGH COMISSIONER FOR HUMAN RIGHTS. Report of the Special Rapporteur on the promotion and protection of the right to freedom of opinion and expression.2011.Disponível em: <http://www2.ohchr.org/english/bodies/hrcou ncil/docs/17session/A.HRC.17.27_en.pdf >. Acesso em: 06/06/2015.

OMMATI, José Emílio Medauar. Uma teoria dos direitos fundamentais. Rio de Janeiro: Lumen Juris, 2014. 248p.

PIOVESAN, Flávia. Direitos humanos e o direito constitucional internacional. $13^{\mathrm{a}} \mathrm{ed}$. São Paulo: Saraiva 2012. 693p.

THE NEXT WEB. 15 of the most expensive domains of all time. Disponível em: $<$ http://thenextweb.com/shareables/2013/08/1 3/15-of-the-most-expensive-domainsof-alltime/>. Acesso em: 01/06/2015. 